A CTUOR'S ABSTRACT OF THIS PAPER ISSUED

BY THE BIBLIOGRAPHIC SERVICE, JELY 7

\title{
A BRIEF NOTE ON "FLOATING" CLAVICLE
}

\author{
EDGAR F. CYRIAX
}

\section{London}

I have ventured to apply the name of "floating" clavicle to a condition which as far as I know has up to the present not been described, namely, one in which the inner end of the clavicle instead of constantly impinging upon and forming a joint with the articular facet on the sternum, lies quite free and moveable.

I am inclined to think that the condition is not so uncommon, and that the reason why it passes unnoticed is simply because it is not looked for, inasmuch as it apparently produces no subjective symptoms; in the cases I have seen the patient himself was not even aware of the abnormality until it was pointed out to him. My attention was first drawn to the condition of floating clavicle about twelve months ago, when I discovered it while examining the joints in a case of articular rheumatism of the left arm; the left sterno-clavicular joint was the one that was involved. Six months later I found another floating clavicle, also on the left side, in a girl of ten who stammered, and recently I found a third case again also on the left side, in an aviator who informed me that he had once had phthisis pulmonum some years previously.

In none of these cases were there any subjective symptoms whatever. They all showed practically the same objective ones, as follows: The inner end of the clavicle was free and was not in contact with the sternum; when the arm was dependent it occupied a position about one quarter of an inch above its fellow on the opposite side: On grasping the sternal end of the clavicle between the forefinger and thumb it was found that it could perfectly easily be moved downwards onto the articular facet on the sternum, and from there with equal facility upwards, inwards, outwards, backwards and forwards. The range of all 
these movements was about the same, namely approximately one quarter inch; the final stage of each movement was somewhat abruptly limited, suggesting that this was done by means of ligaments rather than muscles. The only one of these movements that had any result was the backwards one which caused some irritation of the larynx; none of the others caused even a passing inconvenience, although the inwards movement seemed to exercise a fair amount of pressure on the sterno-mastoid, causing it to bulge locally.

On moving the clavicle away from the sternum, palpation of both articular surfaces could be done with fair accuracy; as far as could be judged both were normal as regards surface and outline. This leads me to suppose that the condition is acquired rather than congenital.

In none of the subjects examined did the condition of the clavicle seem to have any effect on the strength of the muscles or the range of the movements of the shoulder girdle. On endeavouring to replace the clavicle into its joint, this as stated above could readily be done, but displacement occurred as soon as the patient attempted movements which threw any strain on the joint, even when these movements were executed only through a very small range. In two of the cases mentioned medicogymnastic treatment was applied in order to try and effect a permanent reposition of the joint, but in both cases no improvement at all resulted.

In none of the three cases was I able to find any evidence that the floating clavicle was responsible for any of the symptoms, excepting perhaps in the patient who stammered. Her chief impediment was spasmodic action of the diaphragm, and it is not impossible that the free movements of the sternal end of the clavicle may have acted as a continued source of irritation to the phrenic nerve. In her case however pressure of the bone backwards did not aggravate the condition. 